\title{
Meta-análise: seu significado para a pesquisa qualitativa
}

\author{
Meta-synthesis: its meaning in the qualitative research
}

\author{
Maria Aparecida Viggiani Bicudo ${ }^{1}$ \\ mariabicudo@gmail.com
}

\begin{abstract}
Resumo
Este artigo tem como foco o tema metanálise, também denominada metassíntese e meta-análise. Evidencia a compreensão que diferentes autores expõem sobre esse conceito. Apresenta procedimentos em metanálise, assumidos sob o enfoque da pesquisa qualitativa. Traz a compreensão da autora sobre metanálise e os procedimentos de que se vale para conduzir investigações nessa modalidade, quais sejam, os hermenêuticos. Apresenta pesquisas, efetuadas desse modo, como exemplo.
\end{abstract}

Palavras-chave: Metanálise. Pesquisa qualitativa. Hermenêutica.

\begin{abstract}
This paper focuses on meta-synthesis or meta-analysis concepts as they are presented by different authors and the research procedures assumed by them in order to conduct a meta-synthesis research in a qualitative way. Besides, it presents the meta-synthesis conception assumed by this paper's author and the hermeneutical way she works on this qualitative research, with some examples of investigations she has already carried out along her researcher activities.
\end{abstract}

Keywords: Meta-synthesis. Qualitative research. Hermeneutics.

\section{Sobre o tema em foco}

Nas Ciências Humanas, nas da Saúde e, em especial, na da Educação, a modalidade da pesquisa qualitativa tem prevalecido sobre as estatísticas ${ }^{2}$, isso porque sempre se buscam contextualizar o fenômeno investigado, a problemática levantada ou, ainda, a ocorrência de acontecimentos. Em que pese as diferentes modalidades de efetuarem-se pesquisas qualitativas - fenomenológico-transcendentais, fenomenológico-hermenêuticas, etnográficas, 'grounded theory', história oral, estudo de caso, análise de conteúdo, por exemplo, o denominador comum entre elas é o estudo de questões que focam experiências individuais

\footnotetext{
${ }^{1}$ Doutora em Educação. Professora do Programa de Pós-Graduação em Educação Matemática da Universidade Estadual Paulista Júlio de Mesquista Filho, Unesp, campus de Rio Claro, SP. Pesquisadora do CNPq.

${ }^{2} \mathrm{Na}$ área de Educação Matemática, uma pesquisa efetuada por Bicudo e Paulo (2011) evidenciou que a grande quantidade de investigações apresentadas seguiam procedimentos qualitativos.
} 
vivenciadas e relatadas, descrições de situações, narrativas de acontecimentos, ou seja, sempre trabalham com especificidades contextualizadas. Por conseguinte, o contexto histórico, político e social é relevante. Esse o cerne da pesquisa qualitativa, a individualidade e descrição pormenorizada do percebido/observado (BICUDO, 2018, p. 18 e seguintes). E é sobre esse núcleo que incidem muitas críticas advindas de pesquisadores que trabalham com quantidades. Tais pesquisadores tratam de dados pautados em observações de objetividades passíveis de serem quantificadas e estudadas, de acordo com métodos conhecidos e aceitos como válidos por procedimentos tradicionais da ciência positivista. Esses permitem trabalhar com grandes quantidades de ocorrências e admitem probabilidades de haver ou não essas ocorrências, calculadas de acordo com o rigor das ciências exatas e probabilísticas, cujo raciocínio permite generalizações confiáveis, de acordo com os princípios por elas assumidos. A essas críticas, podem-se acrescentar aquelas concernentes à carência de experimentos que possibilitem a validação dos resultados.

Além disso, deve-se ter sob atenção o fato de que as ciências tradicionais, entenda-se aqui as Exatas e da Natureza que se pautaram no modelo lógico da Matemática e nos procedimentos experimentais da Física, sempre almejaram ir além de soluções específicas de problemas, comprovadas como certas, de acordo com o rigor por elas assumido. Buscam reunir soluções em proposições mais gerais e culminam em leis assim como constroem seu edifício teórico. Esse edifício acolhe explicações do acontecido e sustenta projeções para o que poderá ocorrer, com certa probabilidade de ocorrência. Os raciocínios imperantes na construção da argumentação são os indutivos e os dedutivos, encadeados de modo lógico. E devem, para serem aceitos, ser consistentes.

Quando os estudos quantitativos passaram a contar pesadamente com o ferramental estatístico e probabilístico, a reunião entre os diferentes estudos independentes, já efetuados e comprovados como válidos, passou a requer uma meta-análise ou metanálise, cuja raiz etimológica está na língua grega, $\mu \varepsilon \tau \alpha$, que significa 'depois de', e 'além de', e $\alpha v \alpha ́ \lambda v \sigma \eta$, que significa 'análise, para combinar os resultados desses estudos.

Em muitas fontes, tais como Zimmer (2006), Pinto (2013), Passos (2006) e Cassol (2012), encontra-se a explicação de metanálise como uma técnica estatística desenvolvida para integrar os resultados de dois ou mais estudos, sobre um mesmo tema investigado. É agregadora e tende a reduzir os dados a uma unidade de síntese. O procedimento de integrar 
esses resultados pauta-se em uma revisão sistemática da literatura, na análise dos métodos seguidos, dos subtemas trabalhados, das conclusões a que chegaram. Está embasado na compreensão de que a integração de várias pesquisas independentes oferece maior sustentação para trabalhos futuros e balizam modos de observar os fatos de maneira mais rigorosa, pois tende a um padrão.

Vários autores apontam o estatístico Karl Pearson como, provavelmente, o primeiro pesquisador a se valer de técnicas formais para combinar diferentes estudos médicos, no caso. Apontam, também, que o termo meta-análise apareceu pela primeira vez em 1976, com Gene Glass, utilizado em um contexto filosófico. Uma abordagem histórica, suficientemente esclarecedora, é encontrada em Pinto (2013). Zimmer (2006) se vale do termo metassíntese e afirma que esse procedimento também é referido como meta-pesquisa, metanálise qualitativa e análise agregadora. Os autores da língua portuguesa que trabalham com esse procedimento ou que escrevem textos, a fim de esclarecê-lo, preferem o termo metanálise, como se encontra em Passos (2006).

\section{Do que se trata a metanálise}

Quando se fala de modo genérico, entende-se que é meta e análise, ou seja, uma investigação que vai além daquela ou daquelas já realizadas. No caso de pesquisas que procedem de acordo com modalidades qualitativas, as quais sempre culminam em sínteses interpretativas, possibilitadas pelas análises e interpretações dos dados primários, a meta-síntese efetua interpretação das interpretações das pesquisas elencadas como constitutivas dessa análise.

É uma investigação pautada em comparações e análises dos dados primários de pesquisas, tomadas como significativas em relação ao tema posto sob foco. $\mathrm{O}$ alvo é desenvolver um conhecimento teórico que apresente um nível de abstração mais elevado em relação às sínteses interpretativas dos estudos primários, visando à maior possibilidade de aplicações em situações práticas (ZIMMER, 2006).

Vejo a metanálise como um procedimento de estudo importante para as pesquisas qualitativas, não apenas porque, conforme afirma Pinto (2013, p. 1039) 'pode possibilitar maior visibilidade e impacto às inúmeras pesquisas qualitativas conduzidas atualmente na área de Letras' ou porque, conforme Lopes et al (2008, apud Pinto, 2013, p. 1039) 'esforços no sentido de sintetizar estudos qualitativos são vistos como essenciais para atingir proposições 
analíticas mais elevadas e também ampliar a generalização da pesquisa qualitativa', mas porque abre caminhos para a teorização de temas investigados.

Teorização é ação de teorizar, de fazer, de produzir teoria. Na filosofia grega antiga, teoria significa olhar, observar e era empregado para dizer do espectador de jogos e festivais públicos que se extasiava ao assistir, sem participar como jogador ou ator. Nesse contexto olhar, ver ou observar era entendido como ações mentais e a teoria equivalia à contemplação. Em latim, os verbos que dizem dessas ações são contemplari e contemplatio. De acordo com Mora (2001), Platão entende a teoria como contemplação e, para Aristóteles, a teoria mais elevada é o pensar do pensar. Esse filósofo também faz referência à ciência teórica como contrária à ciência prática. Entretanto, para os pensadores da antiguidade, há a tendência de compreender a teoria como superior à ação prática. Hoje, a discussão a respeito da relação entre teoria e prática continua e é explicitada de diferentes modos, os quais não serão explicitados neste texto tendo em vista seu objetivo.

Para o tema deste artigo, trouxe a questão da teorização para dizer de suas significações assumidas em sua historicidade e para explicitar o que compreendo, no rastro desses entendimentos, por teorização. Entendo-a como um olhar, ver, contemplar a totalidade do investigado, em uma ação que reúne, de um só golpe, a visão do todo a que se referem as análises individuais ${ }^{3}$, quando se busca pela interpretação do que dizem sobre o tema investigado. Não se trata de obter uma unidade dessas diferentes análises; também não se trata de uma generalização, importante por ampliar o campo de abrangência do tema investigado. Mas, trata-se de compreender, de modo claro, o que dizem e como dizem. Trata-se de analisar sua consistência, esta olhada como coerência entre a pergunta disparadora da investigação, 'o quê' do investigado, os procedimentos de pesquisa e as interpretações efetuadas.

Entendo que esse processo é importante, pois ilumina um caminho e abre horizontes de compreensões sobre o tema quando oferece um solo temático em que nos locomovemos para novas investigações. É importante, ainda, por fortalecer o campo de investigações sobre um tema e seus modos procedimentais. Assim, não oferecem explicações para vivências situadas, comportamentos analisados etc., nem projeções para futuras ocorrências. Isso está em consonância com o que se almeja com os procedimentos qualitativos: atentar para qualidades, para nuanças de modalidade de estilos de modos de ser, de expressar, de fazer história, de

${ }^{3}$ Denomino como individuais tanto as pesquisas primárias, tomadas em suas individualidades, como as descrições de vivências de sujeitos singulares. 
relatar o ocorrido. Com esta afirmação, estou diferindo da visão de Zimmer acima mencionada.

\section{Como proceder em metanálise}

Zimmer (2006), ao se referir a Sandelowski e Jensen e Allen, menciona três propósitos teóricos inter-relacionados para a efetivação da metanálise: ter cuidado e observar rigor no processo em que se está construindo a teoria, no momento em que resultados ou sínteses interpretativas provenientes de estudos diferentes são reunidos para conduzir o investigado sobre uma temática em um nível teórico mais elevado em relação àquele obtido com único estudo; buscar explicar a teoria mediante como uma análise lateral e dedutiva em que conceitos abstratos de um estudo são preenchidos com significados explicitados em sínteses de resultados de outros estudos; e, atentar para o desenvolvimento teórico dos resultados analisados de um tema que é expressivamente descritivo e compreensivo, portanto, mais completo do que qualquer estudo constitutivo sozinho. Esse autor entende ainda que quaisquer desses propósitos podem ser mutuamente complementares ou sobreporem-se.

Pinto (2013), ao mencionar Castro (2001) e seguir o Cochrane Handbook ${ }^{4}$, aponta sete passos a serem observados ao se efetuar uma metanálise: formulação da pergunta; localização e seleção dos estudos; avaliação crítica dos estudos; coleta dos dados; análise e apresentação dos dados; interpretação dos dados e; aprimoramento e atualização da metanálise.

Para além dessas observações e possíveis sequências de modos de se proceder, pairam muitas questões a respeito da metanálise, quando tomada como meta-estudos de estudos primários. Comparar estudos singulares diferentes é complexo, ainda que seja atraente a efetivação de metanálise, pois anuncia uma possível teorização, possibilidade de dar maior visibilidade às pesquisas qualitativas, de que se obtenham proposições analíticasmais elevadas e de se ampliar a generalização da pesquisa qualitativa, ou seja, sua abrangência.

A linguagem das descrições analisadas é específica para o caso ou para a vivência descrita e carreia características do contexto histórico, político e social da ocorrência em foco. Desse modo, o estudo da linguagem da descrição solicita uma análise interpretativa hermenêutica ou

\footnotetext{
${ }^{4}$ Essa autora assim se refere a essa obra: Cochrane Handbook, produzido pela colaboração Cochrane e CDR Report 4, produzido pelo Center for Reviews and Dissemination, University of York.
} 
de conteúdo ${ }^{5}$. Por conseguinte, ao se definir um tema como significativo por responder a uma interrogação ou pergunta de fundo de uma área de investigação, buscam-se pesquisas qualitativas que tenham como alvo a investigação de aspectos desse tema e da interrogação ou pergunta formulada. Esse procedimento traz também suas complexidades. Mas, atenho-me à questão da análise hermenêutica ou de conteúdo e ao procedimento criterioso de analisar descrição por descrição. A busca é por indícios que apontam para o tema, para que se preencham as lacunas de uma pesquisa com estudos havidos em outra. Esse processo é demorado e exaustivo. Acrescente-se a esses aspectos, a constante atenção do pesquisador e de sua equipe quanto à interrogação ou pergunta e ao tema, para que não percam o fio condutor de sua investigação.

Quanto a busca por pesquisas significativas que visem ao tema e à interrogação ou pergunta formulada, outras questões importantes impõem-se. Concernem à epistemologia e ontologia subjacentes aos procedimentos. As pesquisas trabalham com a mesma visão de mundo e de conhecimento? É preciso que se fique atento aos termos que aparecem em pesquisas qualitativas formuladas segundo diferentes tendências (alguns autores chamam de teorias) como: ground theory, etnografia, fenomenologia, hermenêutica, para citar as mais comuns dentre as muitas importantes. Termos como descrição, vivência, experiência, experiência vivida e contexto são alguns de muitos que comparecem em todas elas. Como são compreendidos no âmbito da visão de mundo e de conhecimento que estão expressando? Como são analisados?

Zimmer (2006) aponta mais um aspecto de crucial importância a ser levado em consideração nos procedimentos que caminham no sentido de dar conta de efetuarem uma meta-síntese de pesquisas qualitativas realizadas sobre um mesmo tema. Trata-se do perigo de, ao longo da metanálise, perderem-se de vista os propósitos dos estudos iniciais, tomados como constituintes dessa análise. Isso porque, a metodologia qualitativa particular e a própria

\footnotetext{
${ }^{5}$ Observo que não as tomo como sinônimos, mas como possibilidades. A hermenêutica busca compreensões de sentidos e de significados na linguagem expressa; o investigador está no mesmo círculo existencial do dito no texto, trazendo nesse estudo o horizonte temporal de si e do analisado. A análise de conteúdo incide sobre as mensagens presentes no texto e o investigador busca construir conhecimento ao analisar o discurso escrito. Para tanto, utiliza-se de processos técnicos relativamente precisos e bastante quantitativos. Essa também se diferencia da análise linguística que provém de estudos da semiótica e toca no lado mais obscuro da linguagem, que é o referente ao vivido e que aponta mais para a intuição essencial do que para o uso correto (lógico gramatical) da linguagem. De acordo com Ricouer (1988, p. 138), 'a análise lingüística não se confina no fechamento da linguagem, mas permanece aberta à experiência e, inversamente, uma eidética descrita no vivido tem implicações lingüísticas, justamente porque é uma eidética e não uma consciência reflexiva, onde apenas se faria reviver o que se viveu, sem o pensar e o dizer'.
} 
questão focada sempre sofrem transgressões, na medida em que a riqueza, a especificidade e os propósitos da pesquisa primeira ficam distantes no processo de efetuarem-se sínteses a caminho da meta-síntese. De acordo com Zimmer (2006, p. 315), "isso levanta a questão de se esse processo de abstração na metasíntese qualitativa realmente viola os princípios do paradigma interpretativo em que os estudos qualitativos estão filosoficamente situados.”.

É importante que se atente para o modo de ser da interpretação da metanálise qualitativa. Concordando com Gadamer (1999), considero que se deva assumir uma atitude rigorosa ao efetuar-se o movimento de interpretação de textos ${ }^{6}$. Estes, como toda e qualquer expressão de vivências humanas, constituem-se pela linguagem.

Isso significa que jamais a interpretação é um movimento reflexivo efetuada na subjetividade de um sujeito, porém, carreia consigo sentidos e significados entrelaçados em uma complexidade, em que estão presentes linguagem e ações contextualizadas socialmente e inerentes ao ser-se no mundo com os outros. Donde há que se adentrar em um movimento dialógico efetuado ao se estar com o dito no texto expresso pela linguagem, com o contexto do texto e com co-pesquisadores que focam o investigado. Essas ideias sobre texto e contexto encontram-se em Ricoeur (1978, 1988). Zimmer (2006) compreende que a meta-síntese é uma interpretação de terceiro nível, pois o primeiro é o efetuado ao trabalhar-se com a descrição das vivências dos sujeitos significativos da pesquisa, constituídos para uma investigação qualitativa específica e o segundo nível é aquele em que o pesquisador analisa e interpreta esses dados. A meta-síntese é interpretação do efetuado nesse segundo nível. Portanto, é a interpretação da interpretação, o que coincide com o exposto por Aristóteles a respeito da teorização, acima mencionada, a qual se refere ao pensar do pensar.

\section{O que compreendo por metanálise}

Entendo a meta-análise como uma retomada da pesquisa realizada, mediante um pensar sistemático e comprometido de buscar dar-se conta da investigação efetuada. Esse 'dar-se conta' significa tomar ciência, mediante uma volta sobre o efetuado. Portanto, trata-se de um movimento reflexivo sobre o que foi investigado, sobre como a pesquisa foi conduzida e,

\footnotetext{
${ }^{6}$ Refiro-me a textos no sentido em que Ricoeur dele trata: como o que é dito é articulado e expresso em um discurso fixado pela escrita tem-se um texto. A transcrição da linguagem oral em signos gráficos aumenta a conservação e a eficácia do que é dito. Isto, porém, não caracteriza o texto. Este atinge a relação do referencial da linguagem com o mundo, pois ele toma o lugar da palavra, a qual diz do mundo (BICUDO, 1991, p. 88,89).
} 
ainda, atentar-se para ver se ela responde à interrogação que a gerou. Para além dessa reflexão, e fazendo parte desse movimento do pensar, incluo aquele de buscar pelo sentido que essa investigação faz para aquele que sobre ela reflete, para seus companheiros de pesquisa, para o tema investigado e para a região de inquérito.

Esse movimento pode ser efetuado individualmente pelo pesquisador, que se volta sobre sua própria investigação, portanto, sobre uma pesquisa; por um grupo de pesquisa que, em colaboração, analisa e reflete sobre um tema que abrange várias pesquisas.

A característica de o processo de metanálise ser reflexivo é apontada por muitos pesquisadores que sobre ela se põem a pensar e expor seu entendimento, como Passos et al. (2006) e Zimmer (2006). Mas, a reflexão exige uma análise sobre os ' dados ' que sustentará o movimento reflexivo. Essa análise, como foi mencionada em item anterior deste artigo, pode ser efetuada de diferentes modos, observando-se os desafios trazidos pela própria metanálise.

Tem-se que: a expressão de sentidos e significados percebidos pelo sujeito é sempre organizada e comunicada mediante linguagem; que essa traz consigo significados constituídos no horizonte histórico do mundo-vida, este tomado como a totalidade do solo mundano com toda sua complexidade, em que sempre somos lançados e solicitados a sermos e nos mantermos sendo. Então a análise dos dados de uma pesquisa qualitativa há que ser interpretativa; capaz de explicitar os entrelaçamentos da rede tecida pela subjetividade e intersubjetividade sempre tomadas no horizonte da temporalidade que abrange presente, passado e futuro em um 'círculo existencial hermenêutico' de retomadas de perspectivas e de prospectivas.

É importante esclarecer, em respeito ao leitor não familiarizado com a filosofia existencial, que círculo existencial hermenêutico difere do círculo de explicações que se remetem umas às outras, denominadas na lógica como 'círculo vicioso'. Vicioso por se fechar em si mesmo, repetindo-se indefinidamente e não se abrindo a outras possibilidades de compreensões. $\mathrm{O}$ círculo existencial hermenêutico diz da situação tomada como certa de sempre estamos no mundo sendo de algum modo. E, ao questionarmos esse mundo, buscamos compreendê-lo e explicá-lo. Vale citar que sempre o fazemos de dentro dele, pois não nos é dado assumir um olhar de fora desse mundo, como se fôssemos um observador universal. Ao procedermos inquirindo-o e compreendendo-o, também nos compreendemos e aos outros, donde nunca 
sermos neutros, mas sempre posicionados. Assim, o investigador há que considerar-se nesse movimento e tomar os devidos cuidados para não permitir que seus pontos de vista imperem na condução da investigação.

Dessa perspectiva, assumo o movimento da metanálise, valendo-me da análise hermenêutica. Como já afirmei acima, entendo meta-síntese como um movimento reflexivo que se volta sobre as análises efetuadas. Busca compreender o sentido do investigado, tendo como norte: a interrogação formulada, o diálogo com os co-sujeitos da pesquisa, entendidos tanto como os que constituem os sujeitos significativos, cujas vivências são descritas ou que se proponham a dar depoimentos sobre suas percepções sobre a pergunta formulada, como as obras de estudadas, e, ainda, os companheiros de grupo de pesquisa.

Eu trabalho com a metanálise, muitas vezes sem mencionar esse termo, porém realizo esse movimento, tendo como foco a própria investigação desenvolvida. Esse é o caso de teses de doutorado e de mestrado que oriento em que, após a pesquisa efetuada e relatada, é aberto mais um item, às vezes denominado capítulo, em que o autor, a autora, retoma o efetuado e abre-se a uma meta-compreensão do investigado. Neste caso, a intenção é dizer do sentido que a pesquisa faz para ele e como a vê no âmbito da 'região de inquérito' com a qual trabalha. Outras investigações por mim orientadas foram realizadas mediante procedimentos de metanálise. Passo a nomear esses trabalhos e destacar algumas passagens das mesmas que revelam o acima afirmado. A seguir, mencionarei um estudo do Grupo de Pesquisa FEM Fenomenologia em Educação Matemática, que coordenei e que foi desenvolvido entre 2006 e 2013, de acordo com procedimentos metanalíticos.

Na dissertação de mestrado de Miarka (2008), há à página 144 o item 3.4 'Efetuando um movimento de meta-compreensão do interrogado', onde o autor retoma sua investigação e efetua um movimento de pensar o pensado, ou seja, de realizar o movimento de compreensão que, conforme Gadamer (1999, p. 436-437), 'vai sempre do todo para as partes e dessas para o todo; movimento esse dialético, caracterizado pela concordância e intrínseco à compreensão. Se não houver concordância entre o todo e as partes nem entre as partes e o todo, o movimento de compreensão fracassa.'

A tese de doutorado de Baumann (2013) à página 346 inicia o último capítulo intitulado 'Meta-compreensão do interrogado e da pesquisa efetuada', subdividido em dois subitens: 'o movimento da pesquisadora' e 'compreensão da formação do professor de matemática dos 
anos iniciais', os quais são tema de investigação. No primeiro, ela efetua uma reflexão sobre o próprio movimento de pesquisar e assim se expressa 'nos colocamos a pensar no movimento de pensar e nos constituirmos, a cada momento, enquanto pesquisadora da área de Educação Matemática'. Explicita:

Esse movimento não é solitário, pois esse constituir-se pesquisadora se dá por meio do envolvimento nas atividades da Pós-Graduação como um todo, no das leituras sobre o tema do trabalho bem como por meio de diálogos com essas leituras e com o grupo de pesquisa e com os próprios sujeitos participantes da investigação (BAUMANN, 2013, p. 346).

No segundo subitem, ela retoma a interrogação propulsora da investigação e reflete sobre o sentido que a pesquisa faz para ela. Assim, afirma

\begin{abstract}
respondendo ao questionamento que nos colocamos no início desta discussão, entendemos que o curso de formação de professores de Matemática dos anos iniciais deveria ser fruto de uma articulação dessas duas áreas (Matemática e Pedagogia) o que exigiria, talvez, um curso diferenciado de ambos os existentes, ainda que englobassem preocupações, propostas e atividades de cada qual. Ou seja, um curso que fosse uma simbiose entre as áreas da Pedagogia e da Matemática" (BAUMANN, 2013 p. 347).
\end{abstract}

As teses de doutorado de Miarka (2011) e Mondini (2013) são constituídas por pesquisas efetuadas mediante procedimentos de metanálise bem como a de Kluber (2012) que coorientei, tendo sido responsável pelos procedimentos e suas respectivas explicações filosóficas.

Miarka interroga a 'etnomatemática'. Para tanto, busca compreendê-la a partir dos autores mais importantes da comunidade científico-acadêmica mundial, que produzem etnomatemática. Investigou quais autores seriam esses dentre aqueles mais referidos em um congresso internacional de etnomatemática e chegou a cinco nomes. Efetuou toda a pesquisa a partir da metanálise dos textos de cada um dos autores. $\mathrm{O}$ autor considerou as obras por eles escritas em um período de tempo relevante na temporalidade da vida profissional desses autores (sujeitos tomados como significativos) e dos textos gerados por entrevistas efetuadas, gravadas e transcritas.

Foram trabalhadas as obras de três autores brasileiros e dois estrangeiros. A metanálise assim efetuada gerou cinco textos analisados hermeneuticamente, um a um, de modo separado. Como uma meta-síntese final, Miarka trabalhou ideias que convergiam e divergiam sobre 
etnomatemática. Fez um percurso que em filosofia denominamos do ôntico ao ontológico que esclarece os sentidos e significados da etnomatemática.

Klüber investigou a Modelagem Matemática trabalhada em Educação Matemática. Também fez uma pesquisa conduzida pela metanálise. Buscou autores significativos brasileiros investigados no universo de autores referidos em trabalhos de um congresso nacional de Modelagem Matemática e analisou hermeneuticamente esses trabalhos, tomando-os na dimensão da obra de cada autor. Efetuou um trabalho de articulação das ideias presentes nas obras desses autores, tomadas como relevantes em relação à interrogação da pesquisa: o que é isto, a Modelagem Matemática na Educação Matemática? Klüber obteve convergências que expressam núcleos de ideias presentes na rede do entendido por esse tema.

Mondini investigou a presença da álgebra na legislação brasileira e pesquisou sobre a mesma desde a educação jesuítica até 1960. O estudo tomou como dados os textos legais que dizem da Álgebra, desde o início da organização escolar no Brasil até a década de 1960. Analisou cada texto de lei em sua historicidade e considerou o contexto sócio-histórico-político que os gerou. A exposição dos movimentos interpretativos e articuladores é apresentada em quadros explicativos. Esta tese é constituída por um estudo filosófico sobre: Hermenêutica enquanto teoria da compreensão; a organização escolar brasileira, estabelecida pelos jesuítas. Expôs uma análise aprofundada do documento ratio studiorum, direcionador das atividades nas escolas jesuíticas e no Estado brasileiro naquele período. Foram estudadas as reformas pombalinas da instrução pública e o impacto das mesmas no sistema escolar brasileiro, principalmente no que diz respeito à Álgebra. Também pesquisou sobre a presença da Álgebra na organização escolar brasileira no período imperial, englobando os documentos legais, editados desde a chegada da família real portuguesa até o fim do império; o período inicial da república brasileira e a legislação que vem com o novo regime político; a organização escolar e as mudanças relativas à Álgebra nessa legislação durante a Era Vargas e o Estado Novo; as propostas educacionais do período em que o Brasil vivenciou o desenvolvimentismo; e as propostas educacionais ocorridas durante o Regime Militar brasileiro e o Movimento da Matemática Moderna. O trabalho conclui com uma metacompreensão do caminho percorrido e aponta o movimento mediante o qual a álgebra foi inserida na organização escolar brasileira. 
Por fim, apresento uma pesquisa de amplo espectro, efetuada pelo FEM - Grupo de Pesquisa Fenomenologia em Educação Matemática, coordenado por mim e formado por pesquisadores de diferentes instituições e partes do Brasil ${ }^{7}$. Essa investigação interrogou: o que é a Pesquisa em Educação Matemática no Brasil? (BICUDO e PAULO, 2011). A interrogação conduziu ao movimento de meta-pesquisa, ou seja, pesquisa sobre a pesquisa, ou ainda, sobre a própria produção da pesquisa, foco do estudo. Destacou a pesquisa efetuada em Educação Matemática no Brasil, tomando o $\operatorname{SIPEM}^{8}$ como o lócus em que pesquisas já avaliadas pelos pares da comunidade científica da Educação Matemática e consideradas apropriadas para serem apresentadas em um Seminário Internacional de Pesquisa são apresentadas e debatidas.

Foram analisados em sua íntegra 216 trabalhos distribuídos, segundo sua temática, pelos doze Grupos de Trabalho desse Seminário. Os trabalhos de cada GT foram analisados por grupos constituídos por duas ou três pessoas pesquisadoras do FEM, segundo procedimentos da análise hermenêutica. O FEM reuniu-se previamente ao início das análises e chegou a um termo de como os trabalhos seriam analisados por todos. Foram consideradas as perguntas, base de uma análise hermenêutica, quais sejam: o que está sendo interrogado, ou seja, o que é perguntado no texto? e como a interrogação conduz à resposta? Isto é, como a argumentação deslancha: com dados empíricos que sustentam as afirmações, com fundamentos teóricos explícitos; pois faz referência à história do assunto ou tema enfocado; aponta a qualificação da bibliografia referida (autores e respectivas procedências, obra original ou traduzida e para que língua) e outras possibilidades descortinadas no processo investigativo, e, finalmente, como o texto responde à interrogação formulada.

Essas perguntas foram retomadas e olhadas à luz da investigação que estava sendo efetuada, de modo que foram reformuladas mediante interpretação do seu significado. Ficaram assim especificadas: 1. O que está sendo interrogado-buscado-problematizado? 2. Como a interrogação conduz à resposta? 3. Como se chega ao buscado ou problematizado? O texto explicita os procedimentos de pesquisa? De que modo? 4. O que o texto responde da pergunta? 5. Qual é a modalidade de pesquisa? a) ensaio teórico, quantitativa etc. b) O texto

\footnotetext{
${ }^{7}$ Membros do FEM: Dra. Maria de Fátima Teixeira Barreto; Dra. Maria Queiroga Amoroso Anastácio; Dra. Rosa Monteiro Paulo; Dra. Tânia Baier; Dra. Renata Cristina Geromel Meneghetti; Dra. Verilda Speridião Kluth; Dra. Ana Paula Purcina Baumann; Dra. Fabiane Mondini; Ms. Jamur Andre Venturin; Dra. Luciane Ferreira Mocrosky; Dra. Marli Regina dos Santos; Dr. Roger Miarka; Ms. Rosemeire de Fátima Batistela; Ms. Tiago M. Klüber e Maria Aparecida Viggiani Bicudo, sua coordenadora.

${ }^{8}$ O SIPEM, Seminário Internacional de Educação Matemática, é um seminário abrigado e mantido pela Sociedade Brasileira de Educação Matemática.
} 
relata uma pesquisa: concluída, em andamento ou projeto de pesquisa? c) a contribuição para a área está explícita no texto? Qual? d) como se apresentam as referências bibliográficas? e) quais os autores referidos.

Esse estudo interpretativo conduziu o movimento de diálogo esclarecedor mediante perguntas dirigidas ao texto e para as respostas que ele revela. Esse procedimento possibilitou a elaboração de uma rede a partir das Categorias Abertas ou Núcleos de Ideias que aglutinam temas, modalidades de pesquisa, tendências teóricas, concepções, conceitos e outros núcleos consteladores revelados durante a investigação.

Trata-se de uma rede de núcleos de significados e significações, que se mostram em sua complexidade na medida em que os dados da rede constituída pelas Categoriais Gerais são trazidos para a interpretação. Esses núcleos foram interligados em uma rede que evidenciou a problemática estudada em Educação Matemática no Brasil: os autores mais referidos em relação a cada tema, os procedimentos de pesquisa assumidos e o respectivo rigor observado, as instituições de origem desses autores mais referidos e a proveniência de sua formação.

Desse modo, pode-se obter um panorama bastante específico da pesquisa em Educação Matemática efetuada no Brasil, sem que se partisse de categorias pré-estabelecidas sobre o que há que ser considerado como uma boa pesquisa. Mas, foram obtidas informações provenientes dos próprios trabalhos que, mediante a análise hermenêutica de seus textos, permitiram a compreensão de seus sentidos e significados para essa pesquisa nesse país.

\section{Referências}

BAUMANN, A. P. Atualização do Projeto pedagógico nos cursos de formação de professores de Matemática dos anos iniciais do Ensino Fundamental: Licenciatura em Pedagogia e Licenciatura em Matemática. 2013, 654 f. (Tese de doutoramento). . Programa de Pós-graduação em Educação Matemática. Doutorado em Educação Matemática. Universidade Estadual Paulista, Rio Claro, 2013

BICUDO, M. A. V. A hermenêutica e o trabalho do professor de Matemática. Caderno de Pesquisa Qualitativa. v. 3 n. 3, São Paulo: Sociedade de Estudos e Pesquisa Qualitativos, 1991, p. $63-96$.

BICUDO, M. A. V. A pesquisa qualitativa olhada para além dos seus procedimentos. In: Bicudo, M. A. V. (org.). Pesquisa Qualitativa segundo a abordagem fenomenológica. São Paulo: Cortez Editora, 2011. 
BICUDO, M. A. V. e PAULO, R. M. Um exercício filosófico sobre a pesquisa em Educação Matemática no Brasil. Bolema, Boletim de Educação Matemática, v. 25, n. 41, p. 251-298. Dezembro, 2011.

CASSOL, V. J. Tecnologias no ensino e aprendizagem de trigonometria: uma meta-análise de Dissertações e teses brasileiras nos últimos cinco anos. 2012. 84f. Dissertação. (Programa de Pós-graduação em Educação em Ciências e Matemática). Pontifícia Universidade Católica do Rio Grande do Sul, Porto Alegre 2012. 84f.

GADAMER, Hans-Georg. Verdade e Método. Traços fundamentais de uma hermenêutica filosófica. (3ª edição). Petrópolis: Vozes, 1999.

MIARKA, R. Concepções de mundo de professores de Matemática e seus horizontes antevistos. 162f. Dissertação. (Programa de Pós-graduação em Educação Matemática). Universidade Estadual Paulista, Rio Claro, 2008. 162f.

Entonomatemática: do ôntico ao ontológico. 427 f. (Tese de doutorado). Programa de Pós-graduação em Educação Matemática, doutorado em Educação Matemática; Universidade Estadual Paulista, Rio Claro, 2011. 427f.

MONDINI, F. A presença da Álgebra na legislação escolar brasileira. (Tese de doutoramento). Programa de Pós-graduação em Educação Matemática, doutorado em Educação Matemática. Universidade Estadual Paulista, Rio Claro:, 2013; 433 f.

MORA, F. J. Dicionário de Filosofia. São Paulo: Edições Loyola, 2001.

PASSOS, C. L. B. e outros. "Desenvolvimento profissional do professor que ensina Matemática: uma meta-análise de estudos brasileiros." Quadrante, v. xv, n 1 e 2, p. 193 219, 2006.

PINTO, C. M. "Metanálise qualitativa como abordagem metodológica para pesquisas em letras". Atos de Pesquisa em Educação. v. 8, n. 3, p. 1033 - 1048, set. dez. 2013.

RICOEUR, P. Du texte à l'action: essais hermeneutique II. Paris: Éditions du Seul, Novembre, 1986.

RICOEUR, P. O discurso da ação. Lisboa: Edições 70, 1988.

KLÜBER, T. E. Uma metacompreensão da Modelagem Matemática na Educação Matemática. 2012. 396 f. Tese (Doutorado em Educação Científica e Tecnológica) - Centro de Ciências Físicas e Matemática, UFSC, Florianópolis, 2012. $396 f$.

ZIMMER, L. Qualitative meta-synthesis: a question of dialoguing with texts. Journal of Advanced Nursing, v. 53, n. 3, p. 311-318, 2006. 